Pacific Journal of Mathematics

STRONGLY REGULAR GRAPHS AND GROUP DIVISIBLE 


\title{
STRONGLY REGULAR GRAPHS AND GROUP DIVISIBLE DESIGNS
}

\author{
MOHAN S. SHRIKHANDE
}

The counting techniques of the author's earlier work on strongly regular graphs are used to prove the converse of a result of R. C. Bose and S. S. Shrikhande on geometric and pseudo-geometric graphs $\left(q^{2}+1, q+1,1\right)$.

0. Introduction. In the present paper, we use the counting techniques of the author's earlier work [5] to prove the converse of a result of R.C. Bose and S.S. Shrikhande [3] on geometric and pseudo-geometric graphs $\left(q^{2}+\right.$ $1, q+1,1)$.

Section 1 is devoted to preliminaries on strongly regular graphs and group divisible designs. We also give a brief description of the problem under consideration and a statement of our main result Theorem 1.1. Section 2 contains the proof of Theorem 1.1 .

We refer to [3] for the necessary background. Throughout this paper $I$ will denote an identity matrix and $J$ a square matrix of all ones. Also $j$ and $O$ will denote row vectors of all ones and zeros respectively. Finally, $|S|$ denotes the cardinality of the set $S$.

1. Preliminary results and the statement of the main result Theorem 1.1.

A strongly regular graph [1] is a graph on $v$ vertices, without loops or multiple edges and whose standard $(0,1)$ adjacency matrix $A$ satisfies

$$
A J=J A=n_{1} J
$$

and

$$
A^{2}=n_{1} I+\lambda A+\mu(J-I-A)
$$

The parameters of a strongly regular graph are then denoted by

$$
v, n_{1}, \lambda, \mu \text {. }
$$


Let $v=m n$ objects ( $=$ treatments) be partitioned into $m$ disjoint sets $S_{i}(i=1,2, \ldots, m)$, each containing $n$ objects. Let two objects be called adjacent if and only if they belong to the same set $S_{i}$. We then get a strongly regular graph, which is traditionally called a group divisible (G.D.) association scheme. The parameters of a G.D. scheme are given by

$$
v=m n, n_{1}=n-1, \lambda=n-2, \mu=0 \quad(n \geq 2) .
$$

We observe that for a G.D. scheme, the $m n \times m n$ adjacency matrix (= association matrix) $C$ has the form

$$
C=\operatorname{diag}\left[J_{n}-I_{n}, J_{n}-I_{n}, \ldots, J_{n}-I_{n}\right]
$$

Suppose now that we have a G.D. scheme on $v=m n$ treatments as above. A G.D. design $D\left(v, b, r, k, m, n, \lambda_{1}, \lambda_{2}\right)$ is an arrangement of these $v$ treatments $t_{1}, t_{2}, \ldots, t_{v}$ into $b$ distinct subsets $B_{1}, B_{2}, \ldots, B_{b}$ (called blocks) satisfying the following conditions:

(1) $\left|B_{i}\right|=k \quad(i=1,2, \ldots, b)$

(2) Each treatment occurs in exactly $r$ blocks.

(3) Two treatments from the same set $S_{i}$ appear together in exactly $\lambda_{1}$ blocks and two treatments from distinct sets $S_{i}$ and $S_{j}$ occur together in exactly $\lambda_{2}$ blocks.

The parameters of a G.D. design are denoted by

$$
v, b, r, k, m, n, \lambda_{1}, \lambda_{2} \text {. }
$$

A G.D. design $D$ is called semi-regular group divisible (S.R.G.D.) if $\boldsymbol{r}$ $>\lambda_{1}$ and $r k=\lambda_{2} v$. Bose and Connor [2] have shown that for a S.R.G.D. design, $m$ divides $k$ and each block contains $k / m$ treatments from each set $S_{i}(i=1,2, \ldots, m)$.

We now indicate the problem considered in the present paper. Let $D$ be a S.R.G.D. design with parameters (1.6). Let $t_{1}, t_{2}, \ldots, t_{v}$ and $B_{1}$, $B_{2}, \ldots, B_{b}$ denote the treatments and blocks of $D$ respectively. Suppose $D$ has the additional property that there exist distinct nonnegative integers $\mu_{1}$ and $\mu_{2}$ satisfying $\left|B_{i} \cap B_{j}\right| \in\left\{\mu_{1}, \mu_{2}\right\}(i \neq j)$. We construct the block graph $B$ of $D$ as follows. Take the vertices of $B$ to be the blocks of $D$. Define blocks $B_{i}, B_{j}(i \neq j)$ to be adjacent if and only if $\left|B_{i} \cap B_{j}\right|=\mu_{1}$.

Let $N$ denote the usual $v \times b(0,1)$ incidence matrix of $D$. Let $C$ be given by (1.5). Define 


$$
A=\left[\begin{array}{ccc}
0 & j_{v} & O_{b} \\
j_{v}^{\prime} & C & N \\
O_{b}^{\prime} & N^{\prime} & B
\end{array}\right] .
$$

We note that $A$ is a symmetric $(0,1)$ matrix of size $b+v+1$, and has zero trace. Therefore $A$ is the adjacency matrix of a graph. We wish to find necessary and sufficient conditions on the parameters of $D$, so that $A$ is strongly regular.

In [3], the converse situation was investigated. There, one starts with a very specific strongly regular graph, namely a pseudo-geometric graph $\left(q^{2}\right.$ $+1, q+1,1) \quad(q \geq 2)$. (See [1] for a general discussion of geometric and pseudo-geometric graphs $(r, k, t))$. The adjacency matrix $A$ of this graph can be brought to the form (1.7), where $C, N, B$ are now $(0,1)$ matrices of the appropriate form. If further, $A$ has the properties $(P)$ and $\left(P^{*}\right)$ as in the notation of [3], then it was shown that $N$ is the incidence matrix of a S.R.G.D. design $D$ and $C$ is given by (1.5). Moreover the blocks of $D$ have two intersection cardinalities $\mu_{1}, \mu_{2}$ and $B$ is the block graph of $D$.

Specifically, the parameters of the S.R.G.D. design $D$ were shown to be

$$
\left\{\begin{array}{l}
v=q\left(q^{2}+1\right), \quad b=q^{4}, \quad r=q^{3}, \quad k=q^{2}+1, \quad m=q^{2}+1 \\
n=q, \quad \lambda_{1}=0, \quad \lambda_{2}=q^{2}, \quad \mu_{1}=1, \quad \mu_{2}=q+1
\end{array}\right.
$$

In this paper, we shall show that there are only two parametrically possible strongly regular graphs $A$, of the form (1.7), which can be obtained from S.R.G.D. designs in the above manner. One of these graphs is pseudo-geometric $\left(q^{2}+1, q+1,1\right)$.

The full content of our main result is the following:

TheOREM 1.1 Let $N$ be the incidence matrix of a S.R.G.D. design D with parameters $v=m n, b, r, k, \lambda_{1}, \lambda_{2}$ having $m$ sets of $n$ treatments each. Suppose any two distinct blocks of $D$ intersect in $\mu_{1}$ or $\mu_{2}\left(\neq \mu_{1}\right)$ treatments. Let $C$ be the association matrix of $D$ and let $B$ be the adjacency matrix of the blocks of $D$.

Then,

$$
A=\left[\begin{array}{ccc}
0 & j_{v} & O_{b} \\
j_{v}^{\prime} & C & N \\
O_{b}^{\prime} & N^{\prime} & B
\end{array}\right]
$$


represents a strongly regular graph if and only if the parameters of $D$ are given by

(1) $v=q\left(q^{2}+1\right), b=q^{4}, r=q^{3}, k=q^{2}+1, m=q^{2}+1$, $n=q, \lambda_{1}=0, \lambda_{2}=q, \mu_{1}=1, \mu_{2}=q+1 \quad(q \geq 2)$

or (2) $v=2 n, b=n^{2}, r=n, k=2, m=2, n$,

$\lambda_{1}=0, \lambda_{2}=1, \mu_{1}=1, \mu_{2}=0 \quad(n \geq 2)$.

Moreover, the corresponding strongly regular graphs $A$ are respectively pseudo-geometric $\left(q^{2}+1, q+1,1\right)$ or pseudo-geometric $(2, n+1,1)$.

2. Proof of Theorem 1.1. Let $D\left(v, b, r, k, m, n, \lambda_{1}, \lambda_{2}\right)$ be a S.R.G.D. design based on $m$ sets of $n$ treatments each. Let $t_{1}, t_{2}, \ldots, t_{v}$ and $B_{1}$, $B_{2}, \ldots, B_{b}$ denote the treatments and blocks of $D$. We assume further that any two distinct blocks of $D$ intersect in $\mu_{1}$ or $\mu_{2}\left(\neq \mu_{1}\right)$ treatments. Then the parameters of $D$ can be taken to be

$$
v=m n, b, r, k, m, n, \lambda_{1}, \lambda_{2}, \mu_{1}, \mu_{2} \text {. }
$$

Let $N, B, C$ and $A$ be as in the statement of Theorem 1.1. Let $m_{i}$ denote the number of blocks intersecting a given block in $\mu_{i}$ treatments $(i=1,2)$. Then clearly

$$
m_{1}+m_{2}=b-1
$$

and

$$
m_{1} \mu_{1}+m_{2} \mu_{2}=k(r-1)
$$

Therefore, $B$ has constant row sum $m_{1}$ given by

$$
m_{1}=\frac{k(r-1)+\mu_{2}(1-b)}{\mu_{1}-\mu_{2}} .
$$

Now, since $D$ is a S.R.G.D. design with incidence matrix $N$, we know from [2], that $N N^{\prime}$ has eigenvalues $r k, r-\lambda_{1}$ and $r k-\lambda_{2} v=0$, with multiplicities $1, m(n-1)$ and $m-1$ respectively. Hence $N^{\prime} N$ has eigenvalues $r k, r-\lambda_{1}$ and 0 with multiplicities $1, m(n-1)$ and $b-m(n-1)-$ 1 respectively. But, we have 


$$
N^{\prime} N=k I+\mu_{1} B+\mu_{2}(J-I-B) .
$$

Hence, from Frobenius' theorem on commuting matrices, $B$ has eigenvalues $\theta_{0}, \theta_{1}, \theta_{2}$ given by

$$
\theta_{0}=\frac{k(r-1)+\mu_{2}(1-b)}{\mu_{1}-\mu_{2}}=m_{1} \text {, with multiplicity } 1
$$

$$
\theta_{1}=\frac{\left(r-\lambda_{1}\right)+\left(\mu_{2}-k\right)}{\mu_{1}-\mu_{2}}, \quad \text { with multiplicity } m(n-1)
$$

$$
\theta_{2}=\frac{\left(\mu_{2}-k\right)}{\left(\mu_{1}-\mu_{2}\right)}, \quad \text { with multiplicity } b-m(n-1)-1
$$

Thus, from Lemma 5, [4], $B$ is strongly regular $\left(b, m_{1}, \alpha, \beta\right)$, where

$$
\alpha=m_{1}+\theta_{1}+\theta_{2}+\theta_{1} \theta_{2}, \beta=m_{1}+\theta_{1} \theta_{2} \text {. }
$$

Let

$$
A=\left[\begin{array}{ccc}
0 & j_{v} & O_{b} \\
j_{v}^{\prime} & C & N \\
O_{b}^{\prime} & N^{\prime} & B
\end{array}\right]
$$

Suppose $A$ is strongly regular $\left(b+v+1, n_{1}, \lambda, \mu\right)$. Any row sum of $A$ is either $v, n+r$ or $k+m_{1}$. Hence, for regularity we must have

$$
n_{1}=v=n+r=k+m_{1} \text {. }
$$

Next, by considering any two treatments or any two blocks which are adjacent or nonadjacent, easy counting arguments in (2.10) give

$$
\lambda=n-1=(n-1)+\lambda_{1}=\mu_{1}+\alpha
$$

and

$$
\mu=k=1+\lambda_{2}=\mu_{2}+\beta \text {. }
$$


From (2.12), we see that $\lambda_{1}=0$. This together with the Bose-Connor property mentioned in $\$ 1$, implies that every block contains exactly one treatment from each set. Hence the parameters (2.1) of $D$ can be taken as

$$
v=m n, b=n^{2} \lambda_{2}, r=\lambda_{2} n, k=m, m, n, \lambda_{1}=0, \lambda_{2}, \mu_{1}, \mu_{2}
$$

Next, consider a treatment $t_{i}$ and a block $B_{j}$ such that $t_{i} \in B_{j}$. Denoting $N=\left(n_{i j}\right), B=\left(b_{i j}\right), C=\left(c_{i j}\right)$, we have from (2.10),

$$
\lambda=\left\|\{ l : c _ { i l } = 1 = n _ { l j } , 1 \leq l \leq v \} \left|+\left\|l: n_{i l}=1=b_{j l}, 1 \leq l \leq b \mid\right\| .\right.\right.
$$

Using the Bose-Connor property, we get

$$
\lambda=\mid\left\{B_{l}: l \neq j, t_{i} \in B_{l} \text { and }\left|B_{l} \cap B_{j}\right|=\mu_{1}\right\} \mid \text {. }
$$

Let $B_{j}=\left\{t_{i}, y_{1}, y_{2}, \ldots, y_{k-1}\right\}, B_{l}=\left\{t_{i}, x_{1}, x_{2}, \ldots, x_{k-1}\right\}$ (say). Since $\lambda_{1}=0$, each pair $\left(t_{i}, y_{p}\right), 1 \leq p \leq k-1$ occurs $\lambda_{2}$ times in the blocks of $D$. Counting the distribution of these pairs in two ways, we get

$$
\lambda=\frac{(k-1)\left(\lambda_{2}-1\right)-\left(\mu_{2}-1\right)(r-1)}{\mu_{1}-\mu_{2}} .
$$

Next, consider a treatment $t_{i}$ and a block $B_{j}$ such that $t_{i} \notin B_{j}$. Then using the Bose-Connor property, a similar type of counting yields

$$
\mu=\frac{(k-1) \lambda_{2}+\left(\mu_{1}-\mu_{2}\right)-r \mu_{2}}{\mu_{1}-\mu_{2}} .
$$

Then, (2.12), (2.17) and (2.13), (2.18) imply that

$$
(n-1)\left(\mu_{1}-\mu_{2}\right)=(k-1)\left(\lambda_{2}-1\right)-\left(\mu_{2}-1\right)(r-1)
$$

and

$$
(k-1)\left(\mu_{1}-\mu_{2}\right)=(k-1) \lambda_{2}-r \mu_{2} .
$$

Then, (2.19) and (2.20) give

$$
\mu_{1}+r-k=(n-k+1)\left(\mu_{1}-\mu_{2}\right)
$$


and

$$
\mu_{2}+r-k=(n-k)\left(\mu_{1}-\mu_{2}\right) \text {. }
$$

Next, using (2.13), (2.12), (2.11) and (2.9), we obtain

$$
\left(\mu_{1}+r-k\right)\left\{\left(\mu_{1}-\mu_{2}\right)^{2}+\mu_{1}-k\right\}=0
$$

and

(2.24) $\left(\mu_{2}+r-k\right)\left\{\left(\mu_{1}-\mu_{2}\right)^{2}+\mu_{2}-k\right\}+\left(\mu_{1}-\mu_{2}\right)^{2}(n-k)=0$.

Thus,

$$
\left(\mu_{1}-\mu_{2}\right)(n-k+1)\left\{\left(\mu_{1}-\mu_{2}\right)^{2}+\mu_{1}-k\right\}=0 .
$$

and

$$
\left(\mu_{1}-\mu_{2}\right)(n-k)\left\{\left(\mu_{1}-\mu_{2}\right)^{2}+\mu_{1}-k\right\}=0 .
$$

Since $\mu_{1} \neq \mu_{2}$, this gives

$$
\left(\mu_{1}-\mu_{2}\right)^{2}+\mu_{1}-k=0 .
$$

Putting $\mu_{1}-\mu_{2} \mp g$ in (2.27) gives

$$
\begin{gathered}
\mu_{1}=k-g^{2} \\
\mu_{2}=k-g^{2}-g .
\end{gathered}
$$

Substituting these values in (2.22) we get

$$
(n+g) \lambda_{2}=(n+g) g .
$$

Hence, either

$$
\lambda_{2}=g \quad(>0) \quad \text { case (a) }
$$

or

$$
n=-g \quad(\geq 2) \quad \text { case (b) }
$$


If case (a) holds, then $k=m=1+\lambda_{2}=1+g$ and $\mu_{1}=g+1-g^{2}$, $\mu_{2}=1-g^{2}$. But $\mu_{1} \neq \mu_{2}$ and $\mu_{1} \geq 0, \mu_{2} \geq 0$ then imply that $D$ has parameters

$$
\left\{\begin{array}{l}
v=m n=2 n, b=n^{2}, r=n, k=2, m=2, n \\
\lambda_{1}=0, \lambda_{2}=1, \mu_{1}=1,-\mu_{2}=0 .
\end{array}\right.
$$

Also, the parameters of $A$ are then

$(2.32) b+v+1=(n+1)^{2}, n_{1}=2 n, \lambda=n-1, \mu=2 \quad(n \geq 2)$.

Thus $A$ is pseudo-geometric $(2, n+1,1)$.

Finally if case (b) holds, put

$$
n=-g=q \quad \text { (say) }
$$

Then (2.20), together with $\lambda_{2} \neq 0, n \geq 2$ implies that $D$ has parameters

$$
\left\{\begin{array}{l}
v=q\left(q^{2}+1\right), \quad b=q^{4}, \quad r=q^{3}, \quad k=q^{2}+1, \quad m=q^{2}+1 \\
n=q, \lambda_{1}=0, \quad \lambda_{2}=q^{2}, \quad \mu_{1}=1, \quad \mu_{2}=q+1, \quad(q \geq 2) .
\end{array}\right.
$$

And in this case, it is easily seen that $A$ has parameters

$$
\left\{\begin{array}{l}
b+v+1=(q+1)\left(q^{3}+1\right), n_{1}=q\left(q^{2}+1\right) \\
\lambda=q-1, \mu=q^{2}+1
\end{array}\right.
$$

Thus, in this case $A$ is pseudo-geometric $\left(q^{2}+1, q+1,1\right)$.

We have therefore established that if $A$ is strongly regular, then $D$ has parameters given by (2.31) or (2.34). Moreover $A$ is then pseudo-geometric $(2, n+1,1)$ or $\left(q^{2}+1, q+1,1\right)$ respectively.

Conversely it can be easily shown that if $D$ has parameters given by (2.31) or (2.34), then $A$ is strongly regular and is pseudo-geometric $(2, n+1,1)$ or $\left(q^{2}+1, q+1,1\right)$ respectively.

This completes the proof of Theorem 1.1.

REMARKS. (i) The existence of S.R.G.D. designs $D$ with parameters of case (1) in Theorem 1.1 and partial geometries $\left(q^{2}+1, q+1,1\right)$ is known for $q$ a prime or prime power (See [1] and [3]).

(ii) The design $D$ with parameters of case (2) in Theorem 1.1 is 
known for any integer $n$ and is constructed as follows: Arrange $n^{2}$ treatments in an $n \times n$ array as

$$
L=\left[\begin{array}{c|c|c|c}
1 & 2 & \cdots & n \\
\hline n+1 & n+2 & \cdots & 2 n \\
\hline \vdots & \vdots & \ddots & \vdots \\
\hline n^{2}-n+1 & n^{2}-n+2 & \cdots & n^{2}
\end{array}\right]
$$

Write down $2 n$ blocks corresponding to the rows and columns of $L$. We get a design $E$ where the blocks are the columns in

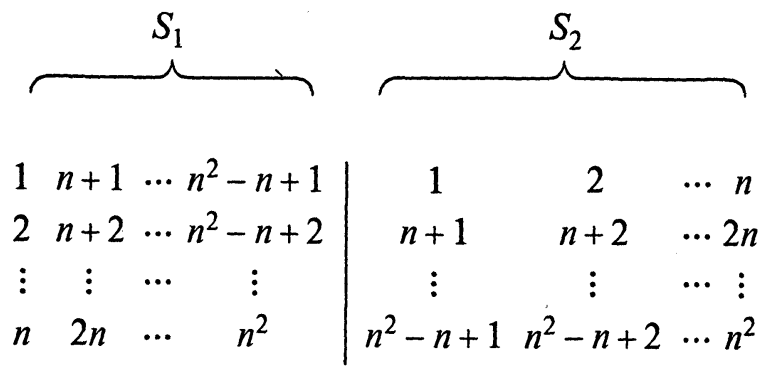

The required design $D$ is the dual of $E$. It is easily seen that in this case the line graph $L_{2}(n+1)$ of the complete bipartite graph $K(n+1, n+1)$ has the same parameters as the graph $A$.

ACKNOWLEDGEMENT. The author wishes to thank the referee for his valuable comments.

\section{REFERENCES}

1. R.C. Bose, Strongly regular graphs, partial geometries and partially balanced designs, Pacific J. Math., 13 (1963), 389-418.

2. R.C. Bose, and W.S. Connor, Combinatorial properties of group divisible incomplete block designs, Ann. Math. Statist., 23 (1952), 367-383.

3. R.C. Bose, and S.S. Shrikhande, Geometric and pseudo-geometric graphs $\left(q^{2}+1, q+1\right.$, 1), J. Geometry, vol 2/1, (1972), 75-94.

4. S.S. Shrikhande, and Bhagwandas, Dusals of incomplete block designs, J. Indian Statist. Assoc., Bulletin 3, (1965), 30-37.

5. M.S. Shrikhande, Strongly regular graphs and quasi-symmetric designs, Utilitas Mathematica, 3 (1973), 297-309. 
UNIVERSITY OF WISCONSIN

AND

UNIVERSITY OF WYOMING

Present address: Pahlavi University

Shiraz, Iran 


\section{PACIFIC JOURNAL OF MATHEMATICS}

\section{EDITORS}

RICHARD ARENS (Managing Editor)

University of California

Los Angeles, California, 90024

\section{R. A. BEAUMONT}

University of Washington

Seattle, Washington 98105

\section{J. DugunDJI}

Department of Mathematics University of Southern California Los Angeles, California 90007

D. Gillbarg AND J. MilgRAM

Stanford University Stanford, California 94305

\section{ASSOCIATE EDITORS}

E. F. BECKENBACH

B. H. NEUMANN

SUPPORTING

UNIVERSITY OF BRITISH COLUMBIA

UNIVERSITY OF CALIFORNIA

MONTANA STATE UNIVERSITY

UNIVERSITY OF NEVADA

NEW MEXICO STATE UNIVERSITY

OREGON STATE UNIVERSITY

UNIVERSITY OF OREGON OSAKA UNIVERSITY
F. WOLF

K. YosHIDA

INSTITUTIONS

UNIVERSITY OF SOUTHERN CALIFORNIA

STANFORD UNIVERSITY

UNIVERSITY OF TOKYO

UNIVERSITY OF UTAH

WASHINGTON STATE UNIVERSITY

UNIVERSITY OF WASHINGTON

AMERICAN MATHEMATICAL SOCIETY

NAVAL WEAPONS CENTER

The Supporting Institutions listed above contribute to the cost of publication of this Journal, but they are not owners or publishers and have no responsibility for its content or policies.

Mathematical papers intended for publication in the Pacific Journal of Mathematics should be in typed form or offset-reproduced, (not dittoed), double spaced with large margins. Underline Greek letters in red, German in green, and script in blue. The first paragraph or two must be capable of being used separately as a synopsis of the entire paper. Items of the bibliography should not be cited there unless absolutely necessary, in which case they must be identified by author and Journal, rather than by item number. Manuscripts, in duplicate if possible, may be sent to any one of the five editors. Please classify according to the scheme of Math. Rev. Index to Vol. ${ }^{39}$. All other communications to the editors should be addressed to the managing editor, or Elaine Barth, University of California, Los Angeles, California, 90024.

100 reprints are provided free for each article, only if page charges have been substantially paid. Additional copies may be obtained at cost in multiples of 50 .

The Pacific Journal of Mathematics is issued monthly as of January 1966. Regular subscription rate: $\$ 72.00$ a year (6 Vols., 12 issues). Special rate: $\$ 36.00$ a year to individual members of supporting institutions.

Subscriptions, orders for back numbers, and changes of address should be sent to Pacific Journal of Mathematics, 103 Highland Boulevard, Berkeley, California 90708.

\section{PUBLISHED BY PACIFIC JOURNAL OF MATHEMATICS, A NON-PROFIT CORPORATION}

Copyright (C) 1974 by Pacific Journal of Mathematics

Manufactured and first issued in the U.S.A. 


\section{Pacific Journal of Mathematics}

\section{Vol. 54, No. $2 \quad$ June, 1974}

John Edward Coury, Walsh series with coefficients tending monotonically to

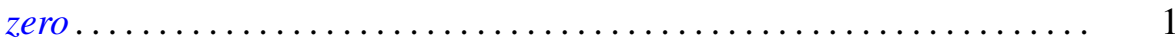

Patrick Michael Fitzpatrick and Walter Volodymyr Petryshyn, Fixed point theorems for multivalued noncompact acyclic mappings ............

Irving Leonard Glicksberg, More on Phragmén-Lindelöf for function

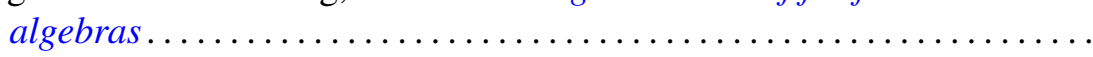

Adilson Goncalves, Structural constants. II .................. 39

Richard P. Gosselin, Closure theorems for affine transformation groups .... 53

Ralph Peter Grimaldi, Baer and UT-modules over domains ........... 59

Edward Grossman, On the prime ideal divisors of $\left(a^{n}-b^{n}\right) \ldots \ldots \ldots \ldots . \ldots 73$

A. Hedayat and Ester Seiden, On the theory and application of sum composition of Latin squares and orthogonal Latin squares.......... .

Gerald L. Itzkowitz, Continuous measures, Baire category, and uniform continuity in topological groups ......................... 115

Francis Masat, Right simple congruences on a semigroup ............ 127

Robert Harvey Oehmke, Right congruences and semisimplicity for Rees matrix semigroups..................................

Qazi Ibadur Rahman and Jan Stankiewicz, Differential inequalities and local valency . . . . . . . . . . . . . . . . . . . . . . . . . . . . . . . . . . . . . 165

William John Reed, Random points in a simplex ................ 183

Mohan S. Shrikhande, Strongly regular graphs and group divisible

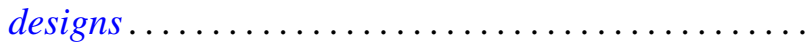

Zahava Shmuely, The structure of Galois connections ... . .

Robert C. Shock, Dual generalizations of the Artinian and Noetherian

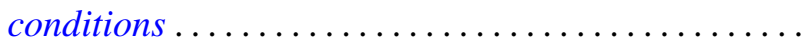

Arne Stray, Approximation and interpolation for some spaces of analytic functions in the unit disc ........................

Eldon Jon Vought, Monotone decompositions into trees of Hausdorff continua irreducible about a finite subset ............

James Wirth, The mapping cylinder axiom for WCHP fibrations ... 263

Gordon S. Woodward, Invariant means and ergodic sets in Fourier analysis... 